\title{
Mathematical Modelling of Bainite Transformation Kinetics
}

\author{
N.A. Chester and H.K.D.H. Bhadeshia \\ University of Cambridge, Department of Materials Science and Metallurgy, Pembroke Street, \\ Cambridge CB2 3QZ, U.K.
}

\begin{abstract}
Steels with a mixed microstructure of allotriomorphic ferrite, bainitic ferrite, retained austenite and martensite have potentially good combinations of high strength and formability. This work describes a kinetic theory for the formation of bainite in steels where the precipitation of carbides is suppressed. The theory is based on the mechanism of transformation. It includes, for example, a nucleation model based on the Magee/Olson/Cohen theory for martensite, growth by a diffusionless mechanism in which sheaves of bainite form by the repeated nucleation of sub-units. These latter platelets grow to a size limited by plastic accommodation of the shape deformation. The theory is compared against experimental data.
\end{abstract}

\section{INTRODUCTION}

Continuously annealed steels, of the type proposed for applications where strength and formability are important, contain a mixed microstructure of allotriomorphic ferrite, bainitic ferrite, martensite and some -austenite which is retained. The purpose of the work presented here was to develop and validate a theory which should permit the estimation of the formation of bainite within such steels.

There has been a variety of models published on the kinetics of the bainite transformation, but only one which is based on a physical mechanism of transformation [1]. Consistent with a vast array of experimental evidence [2], the growth of bainite is taken to be diffusionless, with the carbon partitioning into the residual austenite shortly after the growth of each bainite plate is stifled. This has the important consequence that transformation ceases as soon as diffusionless growth becomes thermodynamically impossible to sustain. The nucleation of bainite, on the other hand, occurs with the paraequilibrium partitioning of carbon. The nucleation event is identified with the rapid dissociation of arrays of pre-existing dislocations (embryos); unlike classical nucleation theory this makes the activation energy for nucleation directly proportional to the chemical driving force, because the latter assists the embryo to overcome an activation barrier to dislocation motion.

The model of Rees and Bhadeshia [1] contained an error in the final integration, so that it has subsequently only been used numerically. In this work, an analytical solution is proposed, tested and extended with the inclusion of a variable platelet size.

\section{NOMENCLATURE}

$\begin{array}{ll}\beta & \text { autocatalysis factor } \beta=\lambda_{1}\left(1-\lambda_{2} \bar{x}\right) \\ B_{s} & \text { Bainite start temperature }\left({ }^{\circ} \mathrm{C}\right) \\ \lambda_{l}, \lambda_{2} & \text { empirical constants } \\ \theta & \text { maximum volume fraction of bainite (at the } T_{0}{ }^{\prime} \text { line) } \\ \xi & \text { normalised volume fraction of bainite } \xi=\frac{v}{\theta} \\ \Delta G_{m}^{0} & \text { initial value of maximum possible free energy change on nucleation }\end{array}$




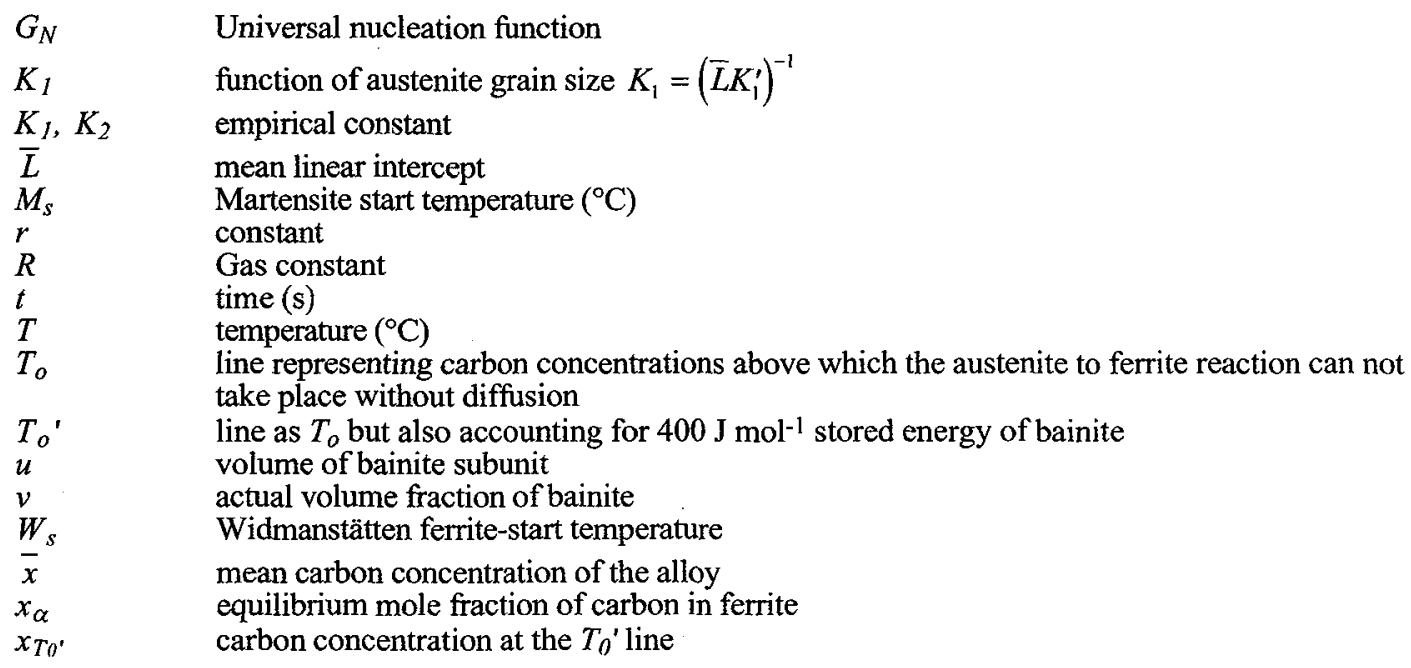

\section{THE THEORY}

The original model $[1,2]$ takes into account the nucleation rate from the point where Widmanstätten ferrite $\left(\alpha_{w}\right)$ formation becomes possible, since both $\alpha_{w}$ and bainite originate from the same nucleus [3]. It is only the growth mechanism which distinguishes these phases. The model also considers the effect of carbon partitioning on free energy change, autocatalysis and the effect of austenite grain size.

These details cannot be discussed here but the rate at which the normalised fraction of bainite changes is given by:

$$
\begin{gathered}
\frac{d \xi}{d t}=\frac{u K_{1}}{\theta}(1-\xi)(1+\beta \theta \xi) \exp \left[-\frac{K_{2}}{R T}\left(1+\frac{\Delta G_{m}^{0}}{r}\right)+\Gamma_{2} \xi\right] \\
\text { where } \Gamma_{2}=\frac{K_{2}\left(\Delta G_{m}^{0}-G_{N}\right)}{r R T}
\end{gathered}
$$

The nucleation rate effect relies on a linear dependence of activation energy on the chemical driving force $\Delta G_{m}$, and the assumption that nucleation rate at the Widmanstätten-start temperature $W_{s}$ is constant for all steels, irrespective of chemical composition.

The effect of carbon partitioning on free energy change was accounted for by assuming that the driving force varies linearly with the extent of reaction, between its initial value $\Delta G_{m}^{0}$ and its final value $G_{N}$ when the reaction terminates.

The autocatalysis factor $\beta$, familiar in martensitic theory, describes the extent to which the formation of one plate stimulates others. It was adjusted to be a function of the mean carbon concentration of the alloy, $\bar{x}$, because carbon build up in the austenite causes a decrease in the driving force for diffusionless transformation thus inhibiting autocatalysis [1].

The number density of grain boundary nucleation sites should be proportional to the grain surface area per unit volume. The term $K_{l}$ is, therefore, inversely related to the mean linear intercept $\bar{L}$ found when measuring the austenite grain size. 
Equation (1) stated above was integrated to give:

$$
t=\frac{\mathrm{e}^{C}}{A(B+1)}\left\{\begin{array}{l}
\mathrm{e}^{E}(\ln |1+B \xi|+f(-(E+D \xi))-f(-E)) \\
-\mathrm{e}^{-D}(\ln (1-\xi)+f(D(1-\xi))-f(D))
\end{array}\right\}
$$

where $A=\frac{u K_{1}}{\theta}, B=\beta \theta, C=\frac{K_{2}}{R T}\left(1+\frac{\Delta G_{m}^{0}}{r}\right), D=\Gamma_{2}, E=\frac{D}{B}, f(x)=\frac{x}{1.1 !}+\frac{x^{2}}{2.2 !}+\frac{x^{3}}{3.3 !}+\ldots$

\section{THE COMPUTER PROGRAM}

The theory stated above has been coded into a computer program which requires an input of chemical composition $\left(\mathrm{C}, \mathrm{Si}, \mathrm{Mn}, \mathrm{Ni}, \mathrm{Mo}, \mathrm{Cr}, \mathrm{V}\right.$ in wt.\%), isothermal transformation temperature $\left({ }^{\circ} \mathrm{C}\right)$ and austenite grain size (micrometers). There are also options for continuous cooling transformation and the intercritical annealing effects.

The other values required in the equation are calculated within the program. The maximum volume fraction $\theta$ is calculated using the Lever Rule applied to the $T_{0}{ }^{\prime}$ curve of the paraequilibrium phase diagram:

$$
\boldsymbol{\theta}=\left(x_{T_{0}}-\bar{x}\right) /\left(x_{T_{0}}-x_{\alpha}\right)
$$

The mean carbon concentration of the alloy $(\bar{x})$ is expressed as a mole fraction, $x_{T 0^{\prime}}$ being the carbon concentration at $T_{0}{ }^{\prime}$ and $x_{x}$ the estimated carbon content of the ferrite.

This version of the isothermal model was used to refine the constants found for the data used in [1] by minimising $\sum\left[\ln \left(t_{p}\right)-\ln \left(t_{m}\right)\right]$ where $t_{p}$ is the predicted time and $t_{m}$ the measured time of bainite reaction.

The original and refined constants are as shown in Table 1 . These refined constants were used for all the predictions shown here.

Table 1: Original and refined constants for Equation 3.

\begin{tabular}{|c|c|c|c|c|}
\hline Constant & $K^{\prime} / u / \mathrm{mm}^{-1} \mathrm{~s}$ & $K_{2} / \mathrm{J} \mathrm{mol}^{-1}$ & $\lambda_{1}$ & $\lambda_{2}$ \\
\hline Original & 33.900 & $2.065 \times 10^{4}$ & 139.00 & 25.460 \\
\hline Refined & 34.456 & $2.098 \times 10^{4}$ & 147.50 & 30.327 \\
\hline
\end{tabular}

Equation 3 was used to predict the time required for a certain volume fraction of bainite to form at a given temperature. Within the program, this time was predicted for a range of volume fractions up to the maximum possible (when the austenite carbon concentration reaches $x_{T_{0}}$ ), thus predicting curves as shown later.

\section{EXPERIMENTAL}

To test the model, dilatation measurements during transformation of a steel of composition $\mathrm{Fe}-0.38 \mathrm{C}$ $1.29 \mathrm{Si}-1.73 \mathrm{Mn}$ (wt.\%) were analysed. The heat-treatments (Figure 1) were carried out in an adapted Thermecmaster Z Simulator which enables measurements of the diametrical dilatation during accurately controlled thermal cycles.

Cylindrical samples ( $8 \mathrm{~mm}$ diameter, $12 \mathrm{~mm}$ length) of the steel were heated by induction in a high vacuum ( $4 \times 10^{-2}$ mbar) with a Pt-PtRh (type R) thermocouple spot welded to the side. After the austenisation heat-treatment $\left(1000^{\circ} \mathrm{C}\right.$ for $\left.300 \mathrm{~s}\right)$ the samples were cooled rapidly to the required hold temperature $\left(T_{H}\right)$ using Helium gas. Six different values: $330,355,380,405,430$, and $455^{\circ} \mathrm{C}$ of $T_{H}$ were chosen between the calculated $B_{s}$ and $M_{s}$ temperatures ( 478 and $323^{\circ} \mathrm{C}$ respectively) to characterise the formation of bainite.

As austenite and bainite are the only phases present during isothermal holding in the bainite region it is possible to convert dilatation measurements, taken during such a hold, into volume fraction transformed. The dilatation measurements were analysed by this method using theory based on [4] and are shown in the results section compared with the model predictions. 


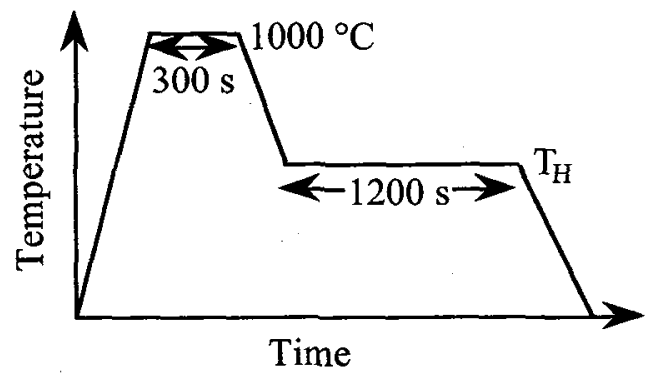

Figure 1: heat treatment used to study the kinetics of the bainite transformation.

\section{RESULTS}

A comparison of the experimental results obtained with steel of composition $\mathrm{Fe}-0.38 \mathrm{C}-1.73 \mathrm{Mn}-1.29 \mathrm{Si}$ (wt.\%) with the model predictions showed that the rate of reaction is predicted correctly for $405^{\circ} \mathrm{C}$ but not for other temperatures. This has been corrected by varying the size of the bainite sub-units $(u$ in the equations) with temperature. Consistent with [5] a linear relation between the volume and temperature was chosen (Figure 2 ) with the sub-unit width $\left(u_{w}\right)$ given by:

$$
u_{w}=0.001077 T-0.2681
$$

where $T$ is temperature in ${ }^{\circ} \mathrm{C}$ and $u_{w}$ is in $\mu \mathrm{m}$.

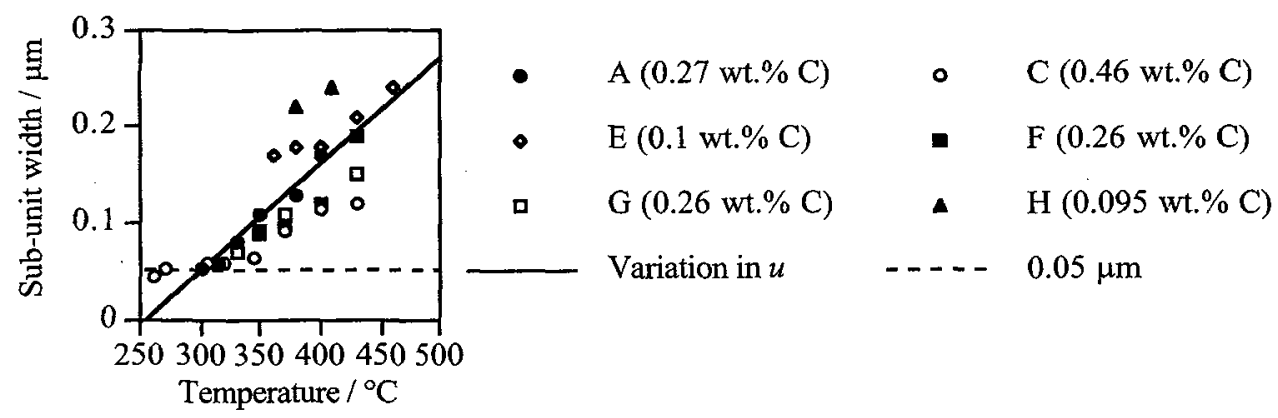

Figure 2: Variation of measured bainite sub-unit width with isothermal transformation temperature. Data from Chang [5] for 6 steels with carbon contents as shown, solid line is best fit chosen for calculation of variation of $u$ for use in model.

A minimum of $0.05 \mu \mathrm{m}$ was set for $u_{w}$ to avoid negative values. The sub-unit thickness $u_{t}$ was assumed to be $10 \mu \mathrm{m}$ and the overall sub-unit volume give by:

$$
u=\left(u_{t}\right)^{2} \times u_{w}
$$

and converted into $\mathrm{mm}^{3}$. This calculation was incorporated into the "constant" $K^{\prime}{ }_{1}^{\prime} u$, the initial value of which was adjusted to be unchanged at $\mathrm{T}=405^{\circ} \mathrm{C}$. 

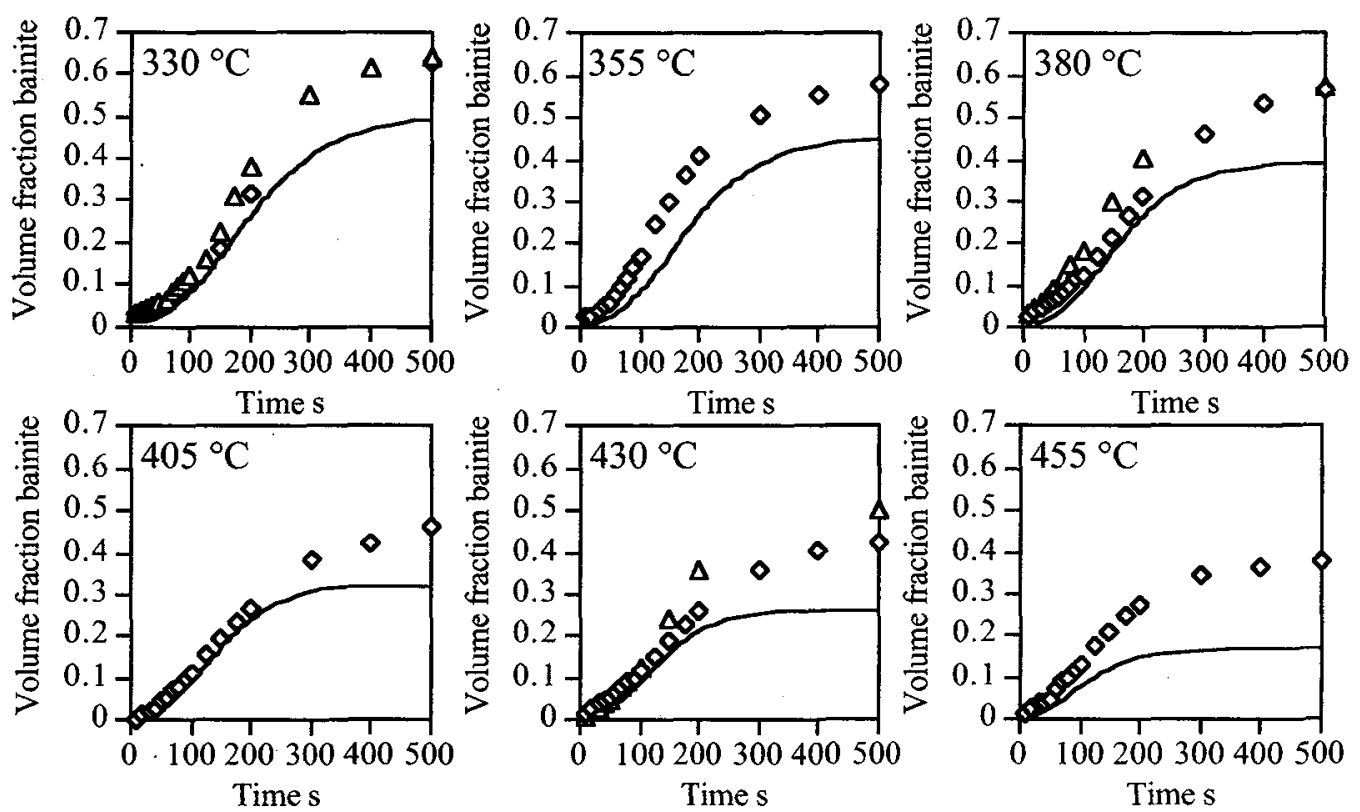

- 1st Measured

$\Delta \quad$ 2nd Measured

Predicted using variable $u$

Figure 3: Measured and predicted isothermal transformation kinetics of bainite for Fe-0.38C-1.29Si-1.73Mn (wt.\%) steel. Prediction including a linear variation in the bainite sub-unit size $(u)$ with temperature.

Figure 3 shows the model predictions with the change in $u$ included. The reaction rate agreement is good but there is a consistent under estimation of the final volume fraction. To investigate this the carbon concentration of the austenite at the final measured volume fraction for each temperature was calculated from the experimental data and is shown in Figure 4 along with calculated $T_{o}$ and $T_{o}$ ' lines. This indicates that the reaction seems to stop between the $T_{o}$ and $T_{o}{ }^{\prime}$ lines. The model previously used $T_{o}^{\prime}$ to calculate the final volume fractions and Figure 5 shows that predictions using $T_{o}$ over predict the final volume fraction.

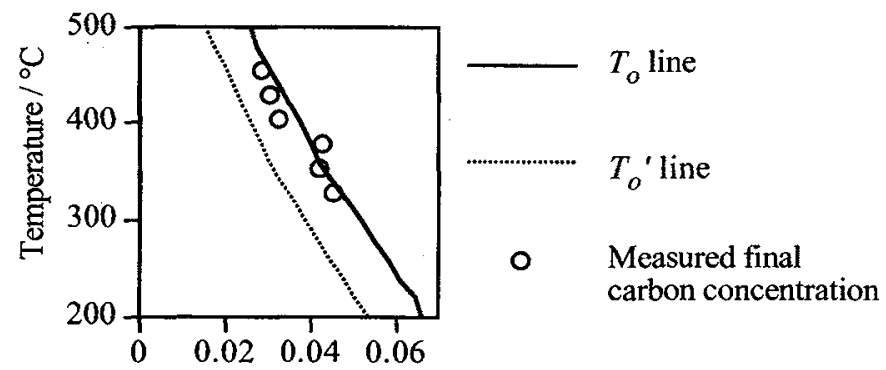

Carbon in austenite / mole fractions

Figure 4: Comparison of final carbon concentrations of austenite in isothermally transformed Fe-0.38C-1.29Si-1.73Mn (wt.\%) steel with calculated $T_{o}$ and $T_{o}^{\prime}$ lines. 

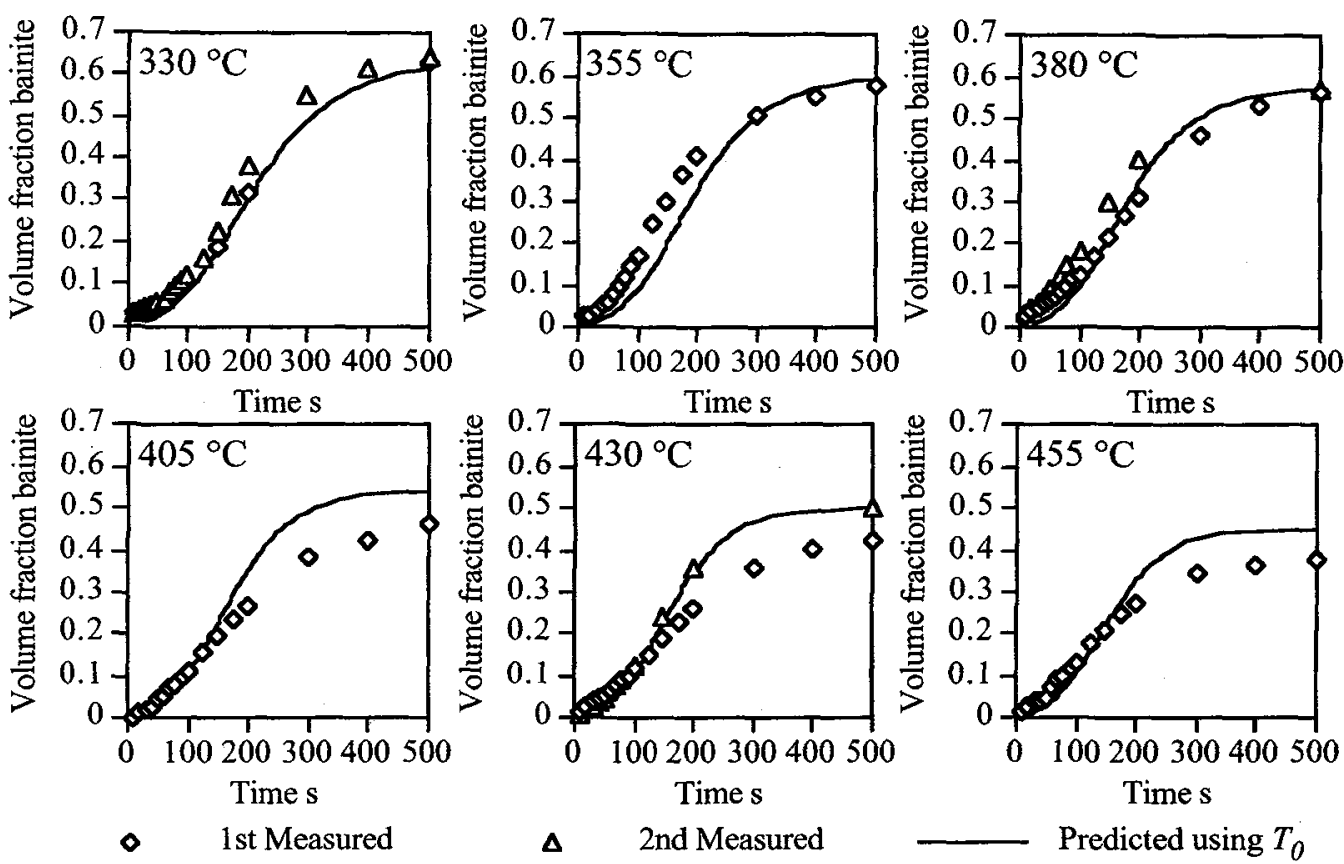

Figure 5: Measured and predicted isothermal transformation kinetics of bainite for Fe-0.38C-1.29Si-1.73Mn (wt.\%) steel. Prediction including variation of bainite sub-unit size with temperature and $T_{o}$ line for maximum volume fraction.

This might be explained by the fact that the $T_{o}$ ' line accounts for $400 \mathrm{~J} \mathrm{~mol}^{-1}$ of stored energy in the bainite. If this energy is reduced by plastic deformation of the surrounding austenite then a higher volume fraction should be able to form. This is to be investigated using an atomic force microscope to measure the surface relief produced by the bainitic transformation.

\section{CONCLUSIONS}

A model for bainite kinetics has been modified to take into account the change in bainite sub unit size with temperature. This gives reasonable agreement with published experimental data and with new results with the possible need to alter the amount of stored energy allowed for within bainite.

\section{Acknowledgements}

The authors are grateful to W.D. Whittaker for his help with the mathematics, P.J. Evans for help with the theory and provision of experimental data, British Steel plc for the materials and financial support, ECSC for financial support, and to Professor Alan Windle for the provision of laboratory facilities.

\section{References}

[1] Rees G.I. and Bhadeshia H.K.D.H., Materials Science and Technology, 8, (1992), 985-993.

[2] Bhadeshia H.K.D.H., J. Phys. (Orsay) 43 (1982) 443-448.

[3] Bhadeshia H.K.D.H., Acta Metall., 29, (1981), 1117-1130.

[4] Bhadeshia H.K.D.H., David S.A., Vitek J.M. and Reed R.W., Materials Science and Technology, 7, (1991), 686-698.

[5] Chang L.C, Bainite Transformation and Novel Bainitic Rail Steels (PhD Thesis, Cambridge, 1995) pp. 46. 